\title{
The Influence of Teachers' Perception and Readiness towards the Implementation of Critical Thinking Skills (CTS) Practice in Mathematics
}

\section{Siti Noor Ismail}

AP., School of Education, Universiti Utara Malaysia, Malaysia, siti.noor@uum.edu.my

\section{Shamsuddin Muhammad}

Dr., Teacher Education Institute, Kelantan, Malaysia, cgdeen1733@yahoo.com

\author{
Abdul Ghani Kanesan \\ Prof., School of Education, Universiti Science of Malaysia, Malaysia, agk@usm.my
}

\section{Ruzlan Md. Ali}

Assoc. Prof., AP., School of Education, Universiti Utara Malaysia, 06010 Sintok, Kedah, Malaysia,ruzlan@uum.edu.my

\begin{abstract}
This study was conducted to identify the level of practice of critical thinking skills (CTS) and to determine whether the dimensions of perception and readiness of the teachers were the predictors of the implementation of the CTS. A cross-sectional quantitative approach using questionnaires have been used on 226 Mathematics teachers teaching in high performing school (HPS), medium performing school (MPS) and low performing school (LPS) in Kelantan, Malaysia. Descriptive statistical analysis showed that the level of practice of CTS in HPS was higher than MPS and LPS. Post-Hoc Multiple Comparisons test also showed no significant differences for perception and teacher readiness mean scores towards CTS between HPS, MPS and LPS. Furthermore, Stepwise's multiple regression analysis shows that perception and teacher readiness is a predictor factor in the practice of applying CTS in the Mathematical learning and teaching process in schools. This study provided a significant contribution towards improving the practice of CTS in Mathematical learning and teaching to realize educational excellence across the 21st century learning that emphasizes high-order thinking skills (HOTS). Hence, teachers should plan their lessons well by selecting effective strategies and teaching and learning materials that will inculcate and enhance CTS in students simultaneously achieving the teaching and learning objectives.
\end{abstract}

Keywords: teacher perception, teacher readiness, critical thinking skill, high-order thinking skill

Citation: Ismail, S. N., Muhammad, S., Kanesan, A. G., \& Ali, R. M. (2019). The Influence of Teachers' Perception and Readiness towards the Implementation of Critical Thinking Skills (CTS) Practice in Mathematics. International Journal of Instruction, 12(2), 337-352. https://doi.org/10.29333/iji.2019.12222a 


\section{INTRODUCTION}

Effective education can provide the people with the critical, creative, innovative and highly skilled human capital development process which is a determining factor in the social, cultural, and economic growth of a country (MEDP 2013-2025 MOE, 2012). This is also in line with the second core found in the National Mission which emphasizes the need of a nation to enhance the knowledge and innovation capabilities among students as well as cultivate first-class minds (MDEP 2006-2010 MOE, 2006). Critical thinking is an important element highlighted by the US Department of Education where this element is an important and significant educational aspect that is used as a tool to develop a highly skilled workforce in the face of the challenges of the 21 st century (Crenshaw, Hale, \& Harper, 2011).

According to Jacob and Sam (2008), critical thinking skills (CTS) and problem solving skills among students have significant positive relationship with Mathematics achievement. The statement is parallel to the findings of the study by Kosiak (2004) which states that CTS has a significant positive relationship with the students' mathematics achievement and is significantly related (Semerci, 2005). Although many of the previous studies (Crenshaw et al., 2011; Napisah et al., 2009; Jacob \& Sam, 2008; Semerci, 2005; Kosiak, 2004) have shown the importance of applying CTS to students in teaching, there are also obstacles in realizing the application of CTS in teaching. Snyder and Snyder (2008) suggest that students should be taught critical thinking process because not all students acquire the skills. According to them, four obstacles often prevent the integration of critical thinking in education, namely (1) lack of training, (2) lack of information, (3) prejudice, and (4) time constraints. These factors are among the key factors that impede the effectiveness of learning and teaching processes that implement CTS elements.

The efficacy of learning and teaching requires the willingness of all parties in implementing the nation's education vision and mission (Sanitah \& Norsiwati, 2012). Therefore, the readiness of Mathematic teachers to accept the responsibility of communicating knowledge and then managing the learning and teaching process effectively as claimed is desirable. This is in line with the findings of the study by Rosnani (2002) which shows that teachers' unreadiness is the most serious problem faced in implementing the Critical and Creative Thinking Skills (CCTS) practice in the classroom. Hence, perceptions and readiness among teachers are crucial for the process of planning, preparing, and managing a variety of hands-on or practical activities that can generate and encourage CTS and constructively among students.

In general, Mathematics teaching in schools has not yet shown a clear direction towards the application and development of critical, creative, and innovative thinking skills among students (Bakry, Md. Nor Bakar \& Firdaus, 2013; Saracho, 2012). However, there has been teaching that is characterized by the application of thinking skills among mathematics teachers. The existence of the application of these thinking skills in the learning and teaching process is not an act of conscious and orderly planning but is merely an embedded or unconscious and incidental (Rajendran, 2001). 
In this regard, the researchers are of the opinion that it is necessary to conduct a study on higher order thinking skills (HOTS) by focusing on the CTS to identify the root cause of weaknesses in these skills among students in Malaysia. This study focuses on the practice of applying CTS in the Mathematical learning and teaching process implemented by teachers in the classroom. In addition, this study is related to perceptions and readiness of teachers to know whether both aspects are as predictors or not as factors in the application of such practices.

\section{THEORETICAL BACKGROUND}

\section{Theory and Concept of Critical Thinking}

Critical thinking is one of the elements in HOTS in addition to creative thinking, problem solving, and decision making (Facione, 1990). The Ministry of Education (MOE) Curriculum Development Division (2012) lists the elements of HOTS consisting of critical thinking, logical thinking, reflective thinking, creative thinking, and cognitive meta, while Fong (2012) adds another element, namely the element of insight. A combination of critical and creative thinking will result in effective thinking and problem solving skills (Treffinger, Isaksen \& Dorval, 2006).

According to Facione (2006), the basic concepts vital to critical thinking are the ability to interpret, analyze, evaluate, infer, clearly define the conceptual, methodological, criterialologic or contextual considerations on judgments, and self-control. This concept is also supported by Paul and Elder (2005) who stated that critical thinking is a process in which the thinker improves the quality of their thinking by taking into account the structural changes inherent in thought and adherence to intellectual standards against them.

According to Bassham (2005), critical thinking covers the various cognitive and intellectual skills needed to identify, analyze and evaluate ideas effectively, find and avoid personal prejudices and bias, formulate and present convincing reasons to support a conclusion, as well as make reasonable and thoughtful decisions about what to believe and what to do. Critical thinking is a kind of thought that is closely linked to reasoning, decision making, and problem solving (Willingham, 2008).

In addition, Chun (2010) states that there are various definitions relating to the concept of critical thinking, but the most appropriate is as a form of thinking at a high level, along with analytical reasoning and problem solving. Critical thinking involves the skills component of an analysis of arguments, making inferences using inductive or deductive reasoning, making judgments or decisions, and solving problems (Lai, 2011). The ability to think critically, scientifically, and systematically is an individual's ability to think in a systematic and structured way to solve learning problems and daily tasks (Cornell Critical Thinking Test, 2004 in Clifford, Boufal, \& Kurtz, 2004). 
Figure 1

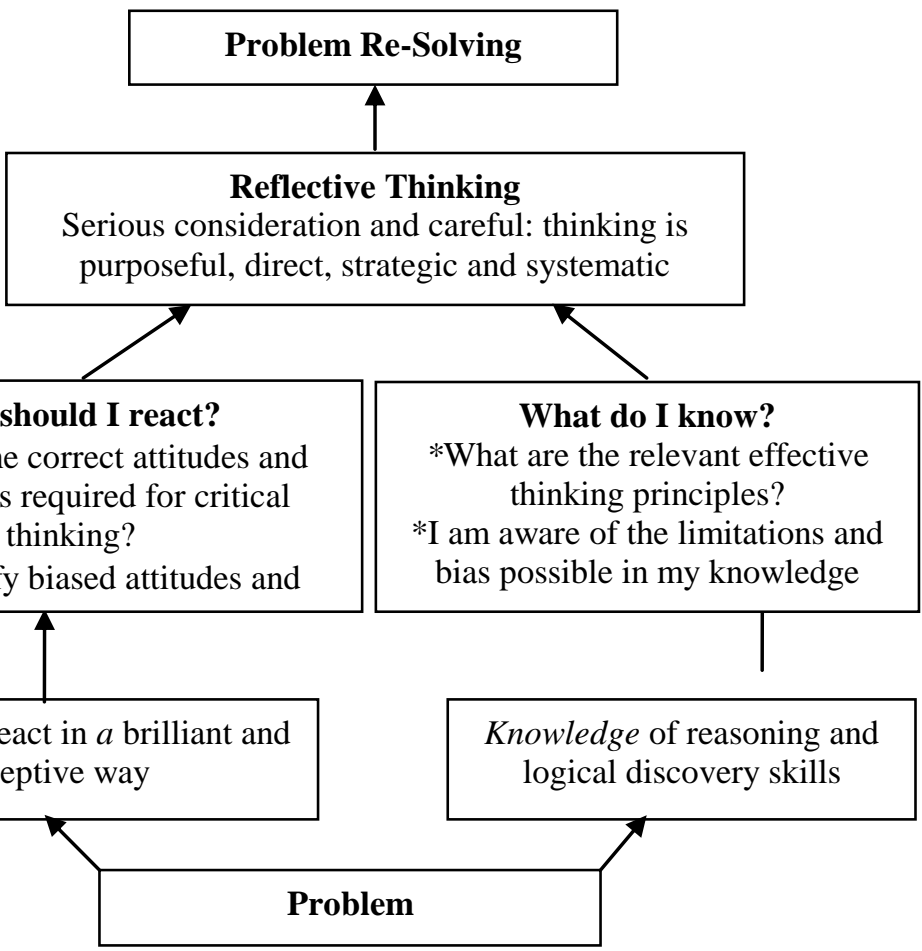

Critical Thinking Model, (Adapted from Zechmeister \& Johnson, 1992)

According to Zechmeister and Johnson (1992), critical thinking involves three major elements; i) attitude and tendency to consider in thought, perception of managing problems and subjects that come at the same time; ii) knowledge of methods for logical reasoning and inquiry; and iii) skills in using the method as shown in Figure 1.

\section{Critical Thinking Model}

One of the objectives of secondary school education in Malaysia is to build and enhance students' intellectual capacity through being rational and thinking critically and creatively (CDC MOE, 1989). In 1993, MOE has identified four models that can be used in the classroom to implement systematic thinking skills programs in schools (CDC MOE, 1993). Following are the models of thinking skills that have been introduced and practiced by teachers in the learning and teaching process in the classroom: -

i) Swartz and Parks Model by Robert Swartz and Sandra Parks

This model is prepared by the National Center for Teaching Thinking in Boston. In Malaysia, this model is known as the 'Boston Model' which presents critical and creative thinking, as well as thoughts to understand and explain.

ii) KWHL Model (Knowledge, What, How and Learnt), where the assumption of information is obtained through critical and creative thinking. 
iii) CoRT 1 Model (Widening the perception) and CoRT 4 Model (Creative and lateral thinking) by Edward de Bono to expand perceptions, and lateral and creative thinking.

iv) Programme Instruction in the Learning of Thinking Skills Model (PILTS) or Intellectual Power Upgrades and Enhancements $(P A D I)$ built by two local academicians, John Arul Phillips and Fatimah Hashim in 1992. This model encompasses conceptual thinking, analytical thinking, critical thinking, creative thinking, and problem solving.

\section{Teacher's Readiness in Applying Critical Thinking Skills}

Planning and preparation describe how teachers design teaching. According to Danielson (2007), planning and preparation is the 'behind the stage' arrangement that organizes classroom teaching. This effort requires a high level of content knowledge to design appropriate teaching to cater for various types of students in their learning. Therefore, the planning and preparation involves demonstrating pedagogical content, demonstrating the knowledge of the students, determining the outcome of the teaching, demonstrating knowledge on resources, create coherent teaching and forming student assessments. These are the demands of every innovation brought into the education system. The failure in making this change will bring failure to the innovation. Lack of knowledge, experience, and capabilities will also cause teachers to be less prepared to deal with and implement planned changes.

In this context, teachers need to have the necessary knowledge, skills, attitudes and interests to make changes, namely by applying CTS in the learning and teaching process in the classroom. The efficacy of teaching and learning requires the willingness of all parties in implementing the vision and mission of national education (Sanitah \& Norsiwati, 2012). Therefore, the effectiveness of Mathematical learning and teaching also depends on the willingness of the teacher in implementing it. Apart from implementing the content of a subject as enshrined in the curriculum, teachers should also apply critical and creative thinking skills during the teaching sessions as recommended by MOE.

In this study, teacher readiness focuses on four aspects namely knowledge, pedagogy, attitude, and interest in Mathematics teaching in the classroom. Hence, the process of planning, setting up, and managing is to act as a platform to provide teachers with the opportunity to demonstrate more hands-on or practical activities that are particularly important in today's education. This type of activity is very important as it will encourage critical and constructive thinking among students. Therefore, these planning and preparation practices will reflect the practice of teachers towards better quality teaching (Hollins, 2011).

Based on the above discussion, this study was conducted to identify whether teachers' perceptions and readiness become a predictor of CTS application in the process of learning and teaching Mathematics at High Performing School (HPS), Medium Performing School (MPS) and Low Performing School (LPS) in Kelantan, Malaysia. 
High Performing School is defined as a school with an ethos, a character, distinctive identity, unique and prominent in all aspects of education. The school also has a very good achievement whereby the School Average Grade (GPS) value is below 2.50 for three consecutive years based on the results of the Malaysian public examination (SPM). Medium Performing School, on the other hand is a school with moderate achievement, where the School Average Grade (GPS) ranges from 3.00 to 5.00 for three consecutive years based on the results of the Malaysian public examination (SPM). While the LowPerforming School has a very low school achievement whereby the School Average Grade (GPS) value exceeds 5.50 for three consecutive years based on the results of the Malaysian public examination (SPM) (Ministry of Education, 2012).

\section{Research Questions}

The following research questions were raised to guide the conduct of the study:

1. What is the level of practice of implementing CTS in the Mathematical teaching and learning process in HPS, MPS and LPS?

2. Are there significant differences in perceptions and readiness of teachers to apply CTS in HPS, MPS and LPS?

3, Are the teachers' perceptions and readiness become a predictor of CTS application in the process of learning and teaching Mathematics?

\section{METHOD}

This study used a cross-sectional survey method involving mean analysis and Post-Hoc Multiple Comparisons. For inference analysis, multiple regression analysis method was used. This method was used to identify whether perception and readiness of the teachers to apply CTS becomes the predictor of applying CTS in the Mathematical learning and teaching process in school. Through this analysis, researchers used theories and concepts presented by Tabachnick and Fidell (2013) and ensured that all regression test conditions were complied with, in terms of linearity, multicollinearity, extreme value, singularity and sample size. There are three multiple regression procedures, that are backward solution, forward solution and stepwise solution. Through this study, researchers used stepwise solution procedures. According to Diekhoff (1992), multiple stepwise regression procedure has advantages compared to other multiple regression procedure because it can avoid the multicollinearity problem existed due to the strong correlation between predictor variables. This correlation is meaningless and it causes analysis to be less accurate. Hence, this problem can be solved through multiple stepwise regression procedures because these correlated variables will not be included in the regression.

\section{Population and Sampling}

According to Fraenkel and Wallen (2006), the whole population is a target population in which the population has the desired characteristics of the respondents in the study. The sampling technique used was proportional random sampling because the number of Mathematics teachers varies according to the school category (Creswell, 2012). In order 
to achieve the purpose of this study, the researcher obtained the number of samples based on Krejcie and Morgan Table (1970), where the total number of research samples was based on the population of each category of school, namely HPS, MPS, and LPS. This means that the sample of the study was randomly selected from each strata based on the percentage of members in the population, where each strata was represented in the sample according to their respective rates. In the HPS category, 25 respondents were randomly selected from 60 Mathematics teachers at 11.1 percent (\%). In the MPS category, 106 respondents were randomly selected from 255 populations at $46.9 \%$, while for the LPS category, 95 respondents were randomly selected from 230 populations at $42.0 \%$. The total number of respondents involved was 226 people. Further information on respondents' demographics is described in the Profile of the respondents section.

\section{Data Collection Tools}

This study employed a standard questionnaire which consists of four parts, namely A, B, $\mathrm{C}$ and D. Part A contains school-related demographics and respondents. Part B contains items to examine the perception of Mathematics teachers towards CTS, part C is to measure the level of readiness of teachers to apply CTS and Part D is to measure the level of CTS application practice in the Mathematical learning and teaching process in the classroom.

In order to assess the perception of teachers towards CTS, researchers have adapted the questionnaire instrument from Thurman's (2009) study, while to measure the level of readiness of the teacher, the researcher adopted and modified items from the questionnaire of Rajendran (1998) and Sanitah and Norsiwati (2012). Whereas for CTS practice instruments, the researchers made modifications and adaptations of Barak \& Shakhman (2008) instruments; Aldegether, (2009); Knapp (2013), and Woo-jeong Shim \& Walczak (2012). The modifications made were the sentence structures so that the items used could be clearly understood by the respondents and in accordance to the suitability of the Malaysian culture and society.

All the instruments conform to the principles of building items in terms of validity and consistency. The internal consistency of these three instruments is estimated by calculating the reliability coefficient, $\alpha$. The result of the reliability analysis for these three instruments demonstrated very high reliability. The Cronbach alpha value for each instrument is between 0.77 and 0.95 . The scores for these three instruments have a very good reliability coefficient of more than 0.70 (Pallant (2013, Sekaran, 2003). The measurement for each variable is to use a five-point Likert scale.

\section{FINDINGS}

\section{Profile of the Respondents}

Descriptive analysis shows the respondents' demographics of each category of school based on gender, Mathematics teaching experience, and also on the aspect of training, whether they have followed HOTS/CCTS training or not, as shown in Table 1. Frequency analysis for gender shows that $145(64.2 \%)$ were female respondents and 81 
$(35.8 \%)$ were male respondents. Frequency analysis results for the teaching and learning aspects of Mathematics showed that 182 respondents $(80.5 \%)$ had more than 10 years of teaching experience, compared to 44 respondents (19.5\%) with 10 years of experience.

Furthermore, the results of the frequency analysis related to the training or thinking skills courses attended showed that 181 respondents $(80.1 \%)$ had participated in HOTS/CCTS training and courses and 45 respondents (19.9\%) had never attended training or courses related to HOTS/CCTS.

Table 1

Respondents Based on Gender, Teaching Experience and Attendance in HOTS/CCTS Courses and Training $(\mathrm{N}=226)$

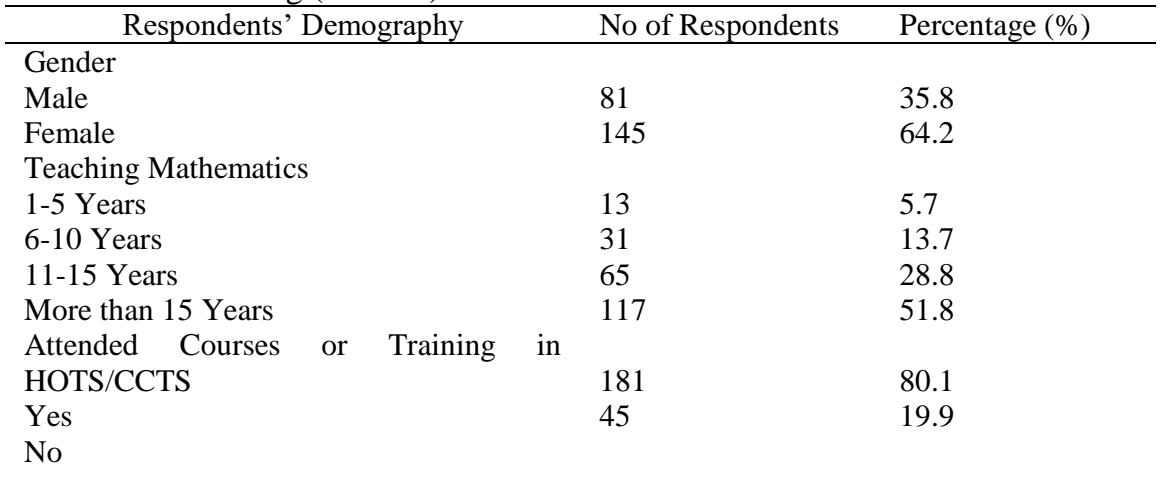

Research Questions 1: What is the level of practice of implementing CTS in the Mathematical teaching and learning process in HPS, MPS and LPS?

Descriptive statistical analysis showed that the mean score for the practice of CTS in the Mathematical learning and teaching process by the teachers in HPS (M $=4.31, \mathrm{SD}=$ .41) was higher than the mean score of CTS application in MPS $(\mathrm{M}=4.07, \mathrm{SD}=.28)$ and LPS $(\mathrm{M}=3.39, \mathrm{SD}=.37)$. The results of the data analysis showed that the mean values for the CTS implementation dimensions in HPS exceeded the 4.00 values and achieved a high level; that is in reflecting and formulating ideas $(\mathrm{M}=4.03, \mathrm{SD}=.67)$, promoting thinking habits $(\mathrm{M}=4.49, \mathrm{SD}=.45)$, creating thinking environment $(\mathrm{M}=$ $4.42, \mathrm{SD}=.47)$, movement towards self-learning $(\mathrm{M}=4.12, \mathrm{SD}=.69)$, and stimulating meta-cognitive $(\mathrm{M}=4.50, \mathrm{SD}=.43)$. The dimensions of stimulating meta-cognitive show the highest mean value while the dimensions reflecting and formulating ideas showed the lowest mean, as shown in Table 2 .

Table 2

Mean Score for Implementation CTS Practice and Dimensions By School Category

\begin{tabular}{lllll}
\hline Dimension & & Mean & SD & Level \\
\hline Implemntation of CTS practice & HPS & 4.31 & .41 & High \\
& MPS & 4.07 & .28 & High \\
& LPS & 3.39 & .37 & Moderate
\end{tabular}




\begin{tabular}{lccll}
\hline \multirow{2}{*}{ Reflecting \& Formulating ideas } & HPS & 4.03 & .67 & High \\
& MPS & 3.72 & .46 & Moderate \\
& LPS & 2.83 & .74 & Low \\
\multirow{3}{*}{ Thinking Habit } & HPS & 4.49 & .45 & High \\
& MPS & 4.26 & .41 & High \\
& LPS & 3.57 & .44 & Moderate \\
\multirow{3}{*}{ Thinking Environment } & HPS & 4.42 & .47 & High \\
& MPS & 4.24 & .38 & High \\
& LPS & 3.66 & .50 & Moderate \\
\multirow{3}{*}{ Self-Learning } & HPS & 4.12 & .69 & High \\
& MPS & 3.85 & .55 & Moderate \\
& LPS & 3.14 & .59 & Moderate \\
Meta cognitive & & & & \\
& HPS & 4.50 & .43 & High \\
& MPS & 4.27 & .43 & High \\
& LPS & 3.76 & .49 & Moderate \\
\hline
\end{tabular}

The findings of data analysis in MPS showed that the dimensions stimulated metacognitive $(\mathrm{M}=4.27, \mathrm{SD}=.43)$, suggesting thinking habits $(\mathrm{M}=4.26, \mathrm{SD}=.41)$, and creating a thinking environment $(\mathrm{M}=4.24, \mathrm{SD}=.38)$ are at a high level. While the dimensions of the movement towards self-learning $(\mathrm{M}=3.85, \mathrm{SD}=.55)$ and reflecting and formulating ideas $(\mathrm{M}=3.72, \mathrm{SD}=.46)$ are at a moderate level. The mean value of the five dimensions has resulted in the high level of practice of CTS implementation at MPS.

Consequently, the results of the analysis also showed that the practice level of the Mathematics Teacher's CTS application in LPS is moderate with four dimensions giving a moderate level of results, ie promoting thinking habits $(\mathrm{M}=3.57, \mathrm{SD}=.44)$, creating a thinking environment $(\mathrm{M}=3.66, \mathrm{SD}=.50)$, movement towards self-learning $(\mathrm{M}=$ $3.14, \mathrm{SD}=.59)$ and stimulating meta-cognitive $(\mathrm{M}=3.76, \mathrm{SD}=.49)$. Meanwhile, only dimensions of reflecting and formulating ideas showed a low level $(\mathrm{M}=2.83, \mathrm{SD}=$ .74).

Research Questions 2: Are there significant differences in perceptions and readiness of teachers to apply CTS in HPS, MPS and LPS?

The data were analyzed using a one way ANOVA analysis method to test the significant differences between two or more independent or unrelated groups. The F distribution was used to test whether there is a difference between two or more groups, and analyze the mean comparison to see the variance differences between the groups.

The homogeneity test of variance for teacher perceptions shows the significant value of Levene test results greater than $0.05(\mathrm{p}>.05)$. Levene statistic shows that the value of $\mathrm{p}$ $=0.22$ has fulfilled the assumption of homogeneity of variance. The results of the oneway ANOVA test showed that the mean score for teacher perception towards CTS in HPS $(\mathrm{M}=4.00, \mathrm{SD}=.54)$ was higher than MPS $(\mathrm{M}=3.89, \mathrm{SD}=.41)$ and LPS $(\mathrm{M}=$ $3.27, \mathrm{SD}=.39)$. One-way ANOVA test results showed that there was a significant 
differences in $\mathrm{p}<.05$ for teachers' perceptions of CTS for all three categories of schools; HPS, MPS, and LPS with F $(2,223)=65.50, \mathrm{p}=.00$ as shown in Table 3 .

Table 3

One Way ANOVA Test on Overall Teacher Perceptions Difference Against CTS Between HPS, MPS, and LPS

\begin{tabular}{llcccc}
\hline Variation Sources & Total Squared & df & Mean squared & F & p \\
\hline Inter Group & 23.11 & 2 & 11.56 & 65.50 & .00 \\
Intra Group & 39.34 & 223 & .18 & & \\
Total & 62.45 & 225 & & & \\
\hline
\end{tabular}

$* \mathrm{p}<.05$

Subsequently, the Post-Hoc Multiple Comparisons tests were made to examine the significant mean differences between the three categories of the school. Based on the results of the Post-Hoc test showed that there was a significant differences in the mean score of teachers' perceptions towards CTS between HPS and LPS, p <.05. There was also a significant difference in the mean score of teachers' perception of CTS between MPS and LPS, $p<.05$. On the other hand, there is no significant differences in the mean score of teachers' perceptions on CTS between HPS and MPS, p> .05 (Table 4).

The Homogeneous Subsets and Means Plots table clearly showed that the mean score for teacher perception towards CTS in LPS $(M=3.27, S D=.39)$ is lower than MPS (M $=3.89, \mathrm{SD}=.41)$ and HPS $(\mathrm{M}=4.00, \mathrm{SD}=.54)$. One-way ANOVA test and Post-Hoc differential test also showed that teachers' perception of CTS in LPS was lower than MPS and HPS.

Table 4

Post-Hoc Follow up Tests for Overall Teachers' Perceptions on CTS Between HPS, MPS, and LPS

\begin{tabular}{cllll} 
MPS, and LPS & \multicolumn{1}{c}{$\begin{array}{c}\text { School Category } \\
(\mathrm{I})\end{array}$} & \multicolumn{1}{c}{$\begin{array}{c}\text { Mean } \\
\text { Difference } \\
(\mathrm{I}-\mathrm{J})\end{array}$} & $\begin{array}{l}\text { Standard } \\
\text { Deviation }\end{array}$ & $\mathrm{p}$ \\
\hline High Performance & Moderate Performance & .11 & .09 & .45 \\
Moderate Performance & Low Performance & $.74 *$ & .09 & .00 \\
Low Performance & Low Performance & -.11 & .09 & .45 \\
& High Performance & $-.74 *$ & .06 & .00 \\
& Moderate Performance & $-.62^{*}$ & .09 & .00 \\
\hline
\end{tabular}

*Mean difference is significant at $\mathrm{p}<.05$

For the readiness level of the teacher, the test results for homogenity variance showed significant value for Levene test results greater than $0.05(\mathrm{p}>.05)$. Levene statistic shows that the value of $\mathrm{p}=0.74$ has fulfilled the assumption of homogeneity of variance. The results of the ANOVA test showed that the mean score for the readiness of the teacher to apply CTS in the Mathematical learning and teaching process at HPS $(\mathrm{M}=4.44, \mathrm{SD}=.33)$ was higher than that of MPS $(\mathrm{M}=4.23, \mathrm{SD}=.32)$ and $\mathrm{LPS}(\mathrm{M}=$ 3.76 , SD =.32). Based on one-way ANOVA test results showed that there was a significant difference in $p<.05$ for the level of readiness of teachers to apply CTS in the 
Mathematical learning and teaching process for all three school categories; HPS, MPS, and LPS with F value $(2,223)=76.76, p=.00$, as shown in Table 5.

Table 5

One Way ANOVA for Overall level of Teacher Readiness in Applying CTS Between HPS, MPS, and LPS

\begin{tabular}{llcccc}
\hline Variation Sources & Total Squared & df & Mean Squared & F & P \\
\hline Inter Group & 15.61 & 2 & 7.80 & 76.76 & .00 \\
Intra Group & 22.67 & 223 & .10 & & \\
Total & 38.27 & 225 & & & \\
\hline
\end{tabular}

$* \mathrm{p}<.05$

The results of the Post-Hoc Multiple Comparisons test also showed that there was a significant differences in the mean score of the readiness level of the CTS students in the Mathematical learning and teaching process between the three categories of schools, namely HPS, MPS, and LPS at p <.05 (Table 6). The Homogeneous Subsets and Means Plots tables clearly indicate that the mean score for the readiness of the teacher to apply CTS in the Mathematical learning and teaching process at LPS $(\mathrm{M}=3.76, \mathrm{SD}=.32)$ was lower than MPS $(\mathrm{M}=4.23, \mathrm{SD}=.32)$ and HPS $(\mathrm{M}=4.44, \mathrm{SD}=.33)$. ANOVA test results and Post-Hoc differences test results showed that the level of teacher readiness of CTS in the Mathematical learning and teaching process in LPS was moderate compared to MPS and HPS which were at high levels.

Table 6

Follow Up Post-Hoc Tests for Overall Teacher Readiness Level Applying CTS Between HPS, MPS, and LPS.

\begin{tabular}{|c|c|c|c|c|}
\hline $\begin{array}{l}\text { School Category } \\
\text { (I) }\end{array}$ & $\begin{array}{c}\text { School Category } \\
\text { (J) }\end{array}$ & $\begin{array}{l}\text { Mean } \\
\text { Difference (I- } \\
\text { J) }\end{array}$ & $\begin{array}{l}\text { Standard } \\
\text { Deviation }\end{array}$ & $\mathrm{p}$ \\
\hline \multirow[t]{2}{*}{ High Performance } & Moderate Performance & $.21 *$ & .07 & .01 \\
\hline & Low Performance & $.69 *$ & .07 & .00 \\
\hline \multirow[t]{2}{*}{ Moderate Performance } & Berprestasi Tinggi & $-.21 *$ & .07 & .01 \\
\hline & Low Performance & $.48 *$ & .05 & .00 \\
\hline \multirow[t]{2}{*}{ Low Performance } & High Performance & $-.69 *$ & .07 & .00 \\
\hline & Moderate Performance & $-.48 *$ & .05 & .00 \\
\hline
\end{tabular}

* Mean difference is significant at $\mathrm{p}<.05$

Research Questions 3: Are the teachers' perceptions and readiness become a predictor of the CTS application in the process of learning and teaching Mathematics?

The results of the multiple Stepwise regression analysis on the perception and readiness of the teachers towards the practice of applying CTS in the Mathematical learning and teaching process indicate that it was significant, as shown in Table 7 . The value of $\mathrm{R}^{2}$ obtained was .39 with $\mathrm{R}^{2}$ modification was .39 . This showed that $39 \%$ of the variance of CTS application practice in the Mathematical learning and teaching process can be explained by the teacher's perception variable towards CTS. Statistical results showed that the value of $F$ was 142.72 and significant $(p<.05)$. This finding showed that the 
regression model of teacher perception towards CTS was significant and applicable to explain the variance of CTS application practices in the Mathematical learning and teaching process $[\mathrm{F}(1,224)=142.72, \mathrm{p}<.05]$.

Next, for teacher readiness variables, the value of $\mathrm{R}^{2}$ obtained was .56 with modified $\mathrm{R}^{2}$ was .56. This showed that $56 \%$ of the variance of CTS application practice in the Mathematical learning and teaching process can be explained by the teacher readiness variable applying CTS. Statistical results show that the value of F was 282.53 and significant $(\mathrm{p}<.05)$. This finding also showed that the regression model of teacher readiness in applying CTS was significant and applicable to explain the variance of CTS application practice in the Mathematical learning and teaching process $[\mathrm{F}(1,224)=$ $282.53, \mathrm{p}<.05]$.

Table 7

Multiple Regression Analysis of Independent Variables with CTS Implementation Practices.

\begin{tabular}{lllllll}
\hline \multicolumn{1}{c}{ Independent Variables } & $\mathrm{R}^{2}$ & Modified $\mathrm{R}^{2}$ & $\mathrm{~F}$ & $\mathrm{p}$ & $\begin{array}{l}\text { Non- } \\
\text { standard } \\
\text { Beta }\end{array}$ & $\begin{array}{l}\text { Standard } \\
\text { Beta }\end{array}$ \\
\hline $\begin{array}{l}\text { Teacher Perception towards } \\
\text { CTS }\end{array}$ & .39 & .39 & $\begin{array}{l}142.7 \\
2\end{array}$ & .00 & .56 & .62 \\
$\begin{array}{l}\text { Teacher Readiness to } \\
\text { Implement CTS }\end{array}$ & .56 & .56 & $\begin{array}{l}282.5 \\
3\end{array}$ & .00 & .90 & .75 \\
\hline
\end{tabular}

Consequently, the combination between the two variables showed the readiness of the teacher to apply CTS $(\beta=.59, \mathrm{p}<.05)$ and teacher perception towards CTS $(\beta=.23, \mathrm{p}$ $<.05)$ contributes $58 \%(\mathrm{R}=.77)$ to the variance change in the practice of CTS implementation in the Mathematics learning and teaching process, as shown in Table 8. Based on the results of the regression analysis, the teacher's perception of CTS and readiness to implement CTS is a factor in the practice of applying CTS in the Mathematics learning and teaching process $[\mathrm{F}(2,223)=158.92, \mathrm{p}<.05]$.

Table 8

Multiple Regression Analysis of Teacher Perception Variables and Teachers' Readiness on CTS Implementation Practice

\begin{tabular}{lccccc}
\hline \multirow{2}{*}{ Independent Variables } & \multicolumn{5}{c}{ Dependent Variables } \\
& \multicolumn{1}{c}{$\begin{array}{c}\text { Non standard } \\
\text { Beta }\end{array}$} & $\begin{array}{c}\text { Unstandardized } \\
\text { Error }\end{array}$ & $\begin{array}{c}\text { Standard } \\
\text { Beta }\end{array}$ & $\mathrm{t}$ & $\mathrm{p}$ \\
\cline { 2 - 6 } & .14 & .21 & & .65 & .51 \\
\hline Constant & .71 & .07 & .59 & 10.3 & $.00^{*}$ \\
Teacher readiness to & & & & 6 & \\
implement CTS & .22 & .05 & .23 & 4.02 & $.00^{*}$ \\
Teacher Perception & & 158.92 & & $.00^{*}$ \\
towards CTS & & .77 & & $.00^{*}$ \\
F Value & & .58 & & $.00^{*}$ \\
R & & & &
\end{tabular}


Since both predictor variables exhibit significance towards the practice of CTS implementation in the Mathematics learning and teaching process, the corresponding regression equation model to be used to predict the practice level of CTS implementation in the learning and teaching Mathematics process by the teacher as stated below :

CTS Implementation Practice

$$
\begin{gathered}
=.14+.22 \text { (teacher perception })+.71 \text { (teacher readiness })+ \\
e(4.02) *(10.36)^{*} \\
* \mathrm{p}<.05, \mathrm{R}^{2}=58 \%
\end{gathered}
$$

\section{CONCLUSION}

Higher Order Thinking Skills (HOTS) and Critical Thinking Skills (CTS) are important field of knowledge and their level of practice in schools is not yet well established. The findings showed that high performance schools have higher CTS application practices compared to medium and low-performing schools. This proves that the theory which states the practice of applying CTS contributes to the academic achievement of students especially for Mathematics subjects is true. With this, the practice of applying CTS is very important to be implemented by teachers in the learning and teaching process to generate and produce students with critical thinking skills and thus, their academic achievement can be enhanced.

Hence, the findings of this study have provided a clearer improvement and enhancement to the application of HOTS especially CTS by highlighting variables that contribute to the practice of applying CTS in schools. This finding also implies the existing theory (Swartz, 2008) and past empirical studies (Aldegether, 2009; Zechmeister \& Johnson, 1992) on the practice of applying CTS and its implementation at school. The findings show that teacher perception variables and teacher readiness contribute to the practice of implementing CTS in schools where there is a significant relationship between these variables. With these variables, the teachers will be more specific and understand what they need to do in order to implement learning and teaching processes that can effectively implement the CTS. This planning and preparation practice will reflect the practice of teachers towards better quality teaching (Hollins, 2011).

Teaching that incorporates CTS into students can improve their understanding better in Mathematics learning and further improve their performance in Mathematics achievement. Hence, it requires a thorough preparation and effective strategy to produce an effective teaching process. Thus, teachers need to be exposed to a variety of knowledge, perceptions, and skills that are closely linked to the practice of applying CTS in advance so that they have a high degree of knowledge, perception and willingness to realize the effective teaching concepts that apply CTS practice. The findings are also in line with the statement by Nair (2012) that school teachers should be trained effectively to use various strategies or methods in their teaching to help them generate and develop CTS and problem-solving skills among students. This shows that CTS among students should be nurtured and applied by teachers to produce students with high-level thinking skills. 
Emphasis on the application of CTS in the classroom not only affects the student's memory of the basic content of the subject (Matheny, 2009), but also reinforces the student's memory of what he has learned. This is in line with the statement by Willingham (2009) which states that the development of the CTS will restore and improve the memory of a student towards the subject matter.

As a conclusion, the application of critical thinking skills in the Mathematic subjects does not only produce students who think critically in solving a problem, but the effect can also reinforce the student's memory of what they are learning. This shows that the CTS element is a catalyst for the mastery of subject matter by the students and subsequently achievement in Mathematics can be enhanced.

\section{REFERENCES}

Aldegether, R. (2009). Teacher educators' opinion and knowledge about critical thinking and the methods they use to encourage critical thinking skills in five female teacher colleges in Saudi Arabia.(Doctoral dissertation). Retrieved from Proquest Dissertations and Theses. (UMI 3352791)

Bakry, Md. Nor Bakar, \& Firdaus. (2013). High-level thinking skills among Mathematics teachers at First Secondary School in Kota Makassar. $2^{\text {nd }}$ International Seminar on Quality and Affordable Education (ISQAE 2013).

Barak, M. \& Shakhman, L. (2008). Fostering higher-order thinking in science class: teachers' reflections. Teachers and Teaching: Theory and Practice, 14(3), 191-208.

Bassham, G. (2005). Critical Thinking: A Student's Introduction (2nd ed.). Boston: McGraw-Hill.

Chun, M. (2010). Talking teaching to (performance) tasks: Linking pedagogical and assessment practices. Dimuat turun daripada http://www.changemag.org

Clifford, J.S., Boufal, M.M., \& Kurtz, J.E. (2004). Personality traits and critical thinking skills in college students: Empirical tests of a two-factor theory. Assessment, $11,169-176$.

Crenshaw, P., Hale, E., \& Harper, S. L. (2011). Producing intellectual labour in the classroom: The utilization of a critical thinking model to help students take command of their thinking. Journal of College Teaching and Learning, 8(7), 13-26.

Creswell, J. W. (2012). Qualitative inquiry \& research design choosing among five approaches (3rd ed.). Los Angelas, CA: Sage Publications, Inc.

Curriculum Development Center. (1989). New School Curriculum Design. Kuala Lumpur: Malaysian Education Ministry

Curriculum Development Center. (1993). Thinking skills: The concepts, models and teaching-learning strategies. Kuala Lumpur: Malaysian Education Ministry.

Curriculum Development Center. (2001). Thinking skills in teaching and learning. Kuala Lumpur: Malaysian Education Ministry.

Curriculum Development Division. (2012). I-Think Programme: Encourage thinking skills. Malaysian Education Ministry. 
Curriculum Development Division. (2012). Standard Mathematics Performance Document Form 1. Malaysian Education Ministry.

Danielson, C. (2007). Enhancing professional practice: A framework for teaching. Alexandria, VA: ASCD.

Diekhoff, G. (1992). Statistics for the social and behavioral sciences. Dubuque: Wm. C. Brown Publishers.

Facione, P. A. (2006). Critical thinking: What it is and why it counts. Millbrae, CA: California Academic Press.

Fong H. K. (2012). Strategies for solving higher order thinking skills (HOTS) mathematics problems at primary and lower secondary level. Training Workshop, RECSAM, Penang.

Fraenkel, J. R., \& Wallen, E. W. (2006). How to design and evaluate research in education. Boston, MA: McGraw-Hill.

Hollins, E.R. (2011). Teacher preparation for quality teaching. Journal of Teacher Education, 62(4), 395-407.

Jacob, S. M., \& Sam. H. K. (2008). Critical thinking skills in online mathematics discussion forums and mathematical achievement. Paper presented at $13^{\text {th }}$ Asian Technology Conference in Mathematics (ATCM 2008), Thailand.

Kosiak, J. J. (2004). Using asynchronous discussions to facilitate collaborative problem solving in college algebra. (Unpublished Doctoral dissertation.) Montana State University, USA.

Krejcie, R. V., \& Morgan D. W. (1970). Determining sample size for research activities. Educational and psychological measurement, 30, 607-610.

Lai, E. R. (2011). Critical Thinking : A Literature Review Research Report. Pearson.

Malaysia Education Ministry. (2006). Education Development Master Pelan (MDEP) 2006- 2010.

Malaysia Education Ministry. (2012). Malaysian Education Development Plan (MEDP) 2013- 2025: Early Report.

Matheny, G. (2009). The knowledge vs. skills debate: A false dichotomy? Leadership,39-40.

Nair, S. (2012). Exploring parents' and teachers' views of primary pupils' thinking skills and problem-solving skills. Creative Education, 03(1), 30-36. doi:10.4236/ce.2012.31005

Napisah Mohd Radzi, Mohd Salleh Abu, \& Shahrin Mohamad. (2009, Disember). Math-oriented critical thinking skills in engineering. Paper presented at International Conference on Engineering Education (ICEED), Kuala Lumpur, Malaysia.

Paul, R., \& Elder, L. (2005). The miniature guide to critical thinking concepts and tools. Dillon Beach CA: Foundation for Critical Thinking. 
Rajendran, N. (1998). Teaching higher order thinking skills in language classrooms: the need for transformation of teaching practice. (Doctoral dissertation). Retrieved from ProQuest Dissertations and Theses. (UMI 9909348).

Rosnani Hashim. (2002). Investigation on the teaching of critical and creative thinking in Malaysia. Jurnal Pendidikan Islam, 10(1), 39-56.

Sanitah Mohd Yusof., \& Norsiwati Ibrahim. (2012). Teacher readiness among first year mathematic teachers' in the implementation of the Primary School Standard Curriculum (KSSR) in Kluang district. Journal of Science and Mathematics Education, 6, 26-38.

Saracho, O. (2012). Creativity theories and related teachers' beliefs. Early Child Development and Care, 182(1), 35 - 44.

Sekaran, U. (2003). Research methods for business. A Skill Building Approach (4th ed.), New York, NY: John Wiley \& Sons, Inc.

Semerci, C. (2005). The influence of critical thinking skills on students' achievement. Pakistan Journal of Social Sciences, 3(4), 598-602.

Snyder. L. G., \& Snyder, M. J. (2008). Teaching critical thinking and problem solving. The Delta Pi Epsilon, 50(2), 90-99.

Swartz, R. (2008). Teaching students how to analyze and evaluate argument in history. The Social Studies, 99(6), 279-280. doi: 10.3200/TSSS.99.6.

Tabachnick, B.G. \& Fidell, L.S. (2013). Using multivariate statistics (6 ${ }^{\text {th }}$ edition). Boston: Pearson Education

Thurman, B. A. (2009). Teaching of critical thinking skills in the English content area in south dakota public high schools and colleges. (Doctoral dissertation). Retrieved from ProQuest Dissertations and Theses. (UMI 3367643).

Treffinger, D. J., Isaksen, S. G., \& Dorval, B. K. (2006). Creative problem solving: An Introduction. Waco, TX: Prufrock Press.

Willingham, D. T. (2008). Critical thinking: Why is it so hard to teach? Arts Education Policy Review, 109, 21-32.

Willingham, D. T. (2009). Why don't students like school? A cognitive scientist answers questions about how the mind works and what it means for the classroom. San Francisco: Jossey-Bass.

Woo-jeong Shim \& Walczak, K. (2012). The impact of faculty teaching practices on the development of students' critical thinking skills. International Journal of Teaching and Learning in Higher Education, 24(1), 16-30.

Zechmeister, E. B., \& Johnson, J. E. (1992). Critical thinking: A functional approach. Pacific Grove, California: Books/Cole Publishing Co. 